\title{
Fumigação de milho para o controle do gorgulho utilizando caule de Tanaecium nocturnum (Bignoniaceae)
}

\author{
Murilo Fazolin(1), Charles Rodrigues da Costa(1), Janaína Estevo de Oliveira Damaceno(1), \\ Elizângela Sampaio de Albuquerque ${ }^{(1)}$, Ana Suzette da Silva Cavalcante ${ }^{(1)}$ e Joelma Lima Vidal Estrela ${ }^{(1)}$
}

(1)Embrapa Acre, Caixa Postal 321, CEP 69901-108 Rio Branco, Acre. E-mail: murilo@cpafac.embrapa.br, charles@cpafac.embrapa.br, janinhaestevo@hotmail.com, elizangela@cpafac.embrapa.br, susyflor@bol.com.br, joelma@cpafac.embrapa.br

\begin{abstract}
Resumo - O objetivo deste trabalho foi avaliar o efeito da fumigação de grãos de milho com segmentos de caules injuriados de Tanaecium nocturnum no controle de Sitophilus zeamais. O delineamento experimental foi inteiramente casualizado, com sete repetições, em parcelas subdivididas. Considerou-se como parcela os tratamentos de fumigação e, como subparcelas, os intervalos de tempo consecutivos tomados a cada 23 dias para as avaliações. Os tratamentos foram: fumigação com $50 \mathrm{~g}$ de segmentos de caules verdes de T. nocturnum por quilograma de grãos de milho, que continham entre 800 e $900 \mathrm{mg} \mathrm{kg}^{-1}$ de $\mathrm{HCN}$; fumigação com $60 \mathrm{mg}$ de pastilhas de fosfeto de alumínio por quilograma de grãos de milho que continham $57 \%$ do princípio ativo; e testemunha (sem aplicação de fumigantes). A infestação por $S$. zeamais e a perda de peso de grãos foram avaliadas nove vezes durante 207 dias. A utilização de $50 \mathrm{~g} \mathrm{~kg}^{-1}$ de segmentos do caule de T. nocturnum para o controle de S. zeamais proporcionou redução da infestação pela praga e da perda de peso de grãos comparável à do fosfeto de alumínio. Esse controle alternativo pode ser adaptado às condições de armazenamento do milho em pequenas propriedades da Amazônia Ocidental.
\end{abstract}

Termos para indexação: Sitophilus zeamais, ácido cianídrico, fumigação de grãos, inseticida botânico.

\section{Fumigation of maize for weevil control using Tanaecium nocturnum (Bignoniaceae)}

\begin{abstract}
The objective of this work was to assess the effect of fumigating corn grains with injured stem parts of Tanaecium nocturnum in the control of Sitophilus zeamais. The experimental design was completely randomized with seven replicates in split plots. The plots consisted of fumigation treatments and the subplots, of consecutive time intervals taken every 23 days for the evaluations. The treatments were: fumigation using $50 \mathrm{~g}$ of green stem parts of T. nocturnum per kilogram of corn grains; which contained between 800 and $900 \mathrm{mg} \mathrm{kg}^{-1}$ HCN fumigation using $60 \mathrm{mg}$ of aluminum phosphide tablets per kilogram of corn grains with $57 \%$ of active ingredient; and control (no fumigation). S. zeamais infestation and weight loss of corn grains were evaluated nine times along 207 days. The use of $50 \mathrm{~g} \mathrm{~kg}^{-1}$ of stem parts of $T$. nocturnum for $S$. zeamais control produced reduction of the pest infestation and of the weight loss of grains comparable to that of aluminum phosphide. This alternative control can be adapted to maize storage conditions on small properties in Occidental Amazon.
\end{abstract}

Index terms: Sitophilus zeamais, cyanhydric acid, grain fumigation, botanical pesticides.

\section{Introdução}

No Brasil, os inseticidas fumigantes são amplamente utilizados para o tratamento curativo de grãos armazenados, com uso da técnica de fumigação ou expurgo. Nas últimas duas décadas, os principais fumigantes utilizados no controle de insetos-praga em grãos armazenados foram a fosfina $\left(\mathrm{PH}_{3}\right)$ e o brometo de metila $\left(\mathrm{CH}_{3} \mathrm{Br}\right)$, este último atualmente de uso proibido por ser um depletor da camada de ozônio. O uso da fosfina tem sido limitado em razão da possibilidade de seleção de populações de insetos-praga resistentes (Pimentel et al., 2007).
Os problemas relacionados à utilização de inseticidas convencionais no controle de insetos-praga de grãos armazenados aumentam a necessidade de desenvolvimento de novas alternativas, principalmente as que possam ser utilizadas em pequenas propriedades rurais, onde, segundo Santos (1993), as principais pragas são Sitophilus zeamais Motsch. (Coleoptera: Curculionidae) e roedores. O gorgulho-do-milho é considerado praga primária por atacar grãos intactos. Sua ação é mais intensa em grãos de milho, mas ele ataca também sorgo, trigo, arroz e alguns produtos alimentícios industrializados como macarrão (Rees, 1996). 
No controle dessa praga, podem ser destacados os efeitos letais promovidos por fumigantes provenientes de óleos essenciais (Coitinho et al., 2006; Estrela et al., 2006). No Acre, Fazolin et al. (2007) utilizaram o óleo essencial de Tanaecium nocturnum (Barb. Rodr.) Bur. \& K. Shum. (Bignoniaceae) para o controle de S. zeamais, tendo observado que as vias de intoxicação por contato em superfície contaminada e fumigação foram mais eficazes em relação à via de contato tópico. Os autores atribuíram a mortalidade à presença do ácido cianídrico (HCN), composto secundário liberado pela hidrólise da mandelonitrila, cianoidrina derivada do benzaldeído, que geralmente é liberada como mecanismo de defesa de plantas e insetos.

Segundo Castro et al. (2004), existe uma grande variação na produção de metabólitos secundários, de acordo com as relações ecológicas, que muda continuamente com o tempo e o espaço. A concentração dos componentes químicos nas plantas depende do controle genético e dos estímulos proporcionados pelo meio, que podem ativar genes biossintéticos que estimulam a superprodução de substâncias de defesa, como no caso de agressão por microrganismos ou insetos-praga. No caso de T. nocturnum, não há referências quanto à variação da produção, em um período de tempo predeterminado, do teor de ácido cianídrico.

Pimentel (2007) determinou que o benzaldeído é o componente majoritário desse óleo essencial (74,7\%), seguido de álcool benzílico (7,9\%), mandelonitrila $(3,9 \%)$ e benzoato de benzila $(3,3 \%)$ e de uma mistura de benzoatos, aldeídos e álcoois $(4,5 \%)$. No entanto, se for considerada a sua utilização prática no controle de $S$. zeamais, Fazolin et al. (2007) verificaram algumas limitações relacionadas à alta reversibilidade e instabilidade do produto, aliada ao baixo rendimento de extração, além da possibilidade, segundo Paes (2008), de que o óleo essencial interfira negativamente no potencial de germinação de sementes. Aqueles autores constataram ainda que o ácido cianídrico é liberado naturalmente pelas folhas e talos da planta de T. nocturnum quando sofrem danos. Por essa razão, os índios da aldeia de Gotira, no rio Fresco-Xingu (Gottlieb et al., 1981), Kayapós, no Pará (Kerr \& Posey,1991) e Wayãpi, na Guiana Francesa (Gentry, 1992), utilizam esse cipó para, entre várias outras aplicações, controlar ou enfraquecer abelhas e formigas.
O objetivo deste trabalho foi avaliar o efeito da furmigação de grãos de milho com segmentos de caules injuriados de T. nocturnum no controle S. zeamais.

\section{Material e Métodos}

Os experimentos foram realizados no campo experimental da Embrapa Acre (67\% $42^{\prime} 19^{\prime \prime S}$, $10^{\circ} 01^{\prime} 30^{\prime \prime} \mathrm{W}$, altitude de $184,4 \mathrm{~m}$ ) localizada na Rodovia BR 364, Km 14 sentido Rio Branco-Porto Velho, no município de Rio Branco, AC.

Levando em consideração a variação da produção de metabólitos secundários das plantas durante períodos pré-estabelecidos, diferentes estruturas vegetais de $T$. nocturnum foram coletadas na área florestal da Embrapa Acre, para que fosse determinada a concentração do HCN. Foram efetuadas coletas mensais durante um ano, tendo-se considerado os valores médios das concentrações do $\mathrm{HCN}$ em razão do período chuvoso da região.

No laboratório, o material foi separado e classificado em caules grossos (de 0,7 a $1,5 \mathrm{~cm}$ de diâmetro), caules finos (de 0,6 a $0,7 \mathrm{~cm}$ de diâmetro), folhas velhas e folhas novas, e submetido à quantificação do teor de ácido cianídrico segundo os métodos de Bradbury et al. (1999).

Optou-se por utilizar segmentos finos de caules de T. nocturnum para o tratamento de expurgo, embora não apresentassem os maiores teores de ácido cianídrico em comparação a outras estruturas da planta ao longo do ano, em razão do aspecto de preservação das plantas do cipó, quando da coleta de material in situ. Observou-se que a recuperação vegetativa é mais rápida quando são extraídos segmentos de caule em comparação à extração das folhas, que apresentam maiores teores do ácido. Observou-se também que as folhas liberam maior quantidade de água em comparação com os caules e promovem o aumento da umidade na massa de grãos de milho, a qual favorece a infecção de fungos.

Avaliações de laboratório foram realizadas para determinar previamente a concentração de talos de T. nocturnum a ser utilizada no tratamento de grãos de milho armazenados em paiol.

Foram utilizados como parcelas experimentais potes de vidro com capacidade de 1,44 L, com tampa hermética. Em cada pote foram colocados $800 \mathrm{~g}$ de grãos de milho cv. BR-473, com teor de água conhecido, que serviram de substrato para 25 adultos de $S$. zeamais sem idade definida, soltos livremente na massa de grãos. 
Após 15 dias de adaptação, foram determinadas as faixas de concentrações de talos de T. nocturnum entre 10 e $100 \mathrm{~g} \mathrm{~kg}^{-1}$ e selecionadas aquelas que causassem mortalidade em valores entre 0 e $100 \%$.

Segmentos de caules finos de T. nocturnum, que continham em média $850 \mathrm{mg} \mathrm{kg}^{-1}$ de $\mathrm{HCN}$ na matéria verde, foram utilizados. O material, após sofrer injúrias mecânicas por esmagamento, foi pesado e introduzido na massa de grãos de milho em cada concentração a ser avaliada. Todos os potes foram transferidos para sala climatizada com temperatura de $25 \pm 2^{\circ} \mathrm{C}$, umidade relativa de $60 \pm 5 \%$ e fotófase de 12 horas.

Foram utilizados adultos de $S$. zeamais, obtidos de uma criação em sacos de polietileno, que continham grãos de milho da cv. BR-473 naturalmente infestados pela praga. Os indivíduos utilizados nas avaliações pesaram em média $3,2 \mathrm{mg}$, não tiveram idade definida e não foram sexados.

$\mathrm{O}$ delineamento experimental foi inteiramente casualizado, com quatro repetições. Cada bioensaio foi repetido três vezes. Após 120 horas, foi avaliada a mortalidade dos insetos para a realização da análise de Probit, modelo baseado em um modelo toxicológico pré-estabelecido. No entanto, essa análise mostrou-se inadequada para determinar a concentração letal 50 $\left(\mathrm{CL}_{50}\right)$ do caule da planta, o que foi demonstrado pelo baixo valor de probabilidade apresentado pelo teste do quiquadrado de Pearson $(\mathrm{p}=0,00001)$, que afere a adequabilidade desse modelo para a relação dose-resposta, assim como o valor do intervalo de confiança da $\left(\mathrm{CL}_{50}\right)(1,0898 \mathrm{mg})$ que variou de 0,03988 a $18,45339 \mathrm{mg}$ de caules de T. nocturnum por grama de grão.

Dessa forma, avaliou-se a relação concentração de caules de $T$. nocturnum x mortalidade de adultos de S. zeamais por análise de regressão polinomial utilizandose o SAS (SAS Institute, 2001).

Outro experimento foi desenvolvido, no período de março a outubro de 2008, em paiol de madeira suspenso do solo e coberto por telha de amianto. Com um termômetro digital, foram registradas diariamente as temperaturas máximas e mínimas no interior do paiol durante o período experimental. As variações médias apresentadas foram de $38,5 \pm 2^{\circ} \mathrm{C}$ e $18,3 \pm 1^{\circ} \mathrm{C}$ para as temperaturas máximas e mínimas, respectivamente.

As parcelas experimentais foram constituídas de sacos de polietileno com $25 \mathrm{~kg}$ de grãos de milho. Cada saco foi infestado com 200 adultos de $S$. zeamais e permaneceu assim, em adaptação, por 45 dias. Caules injuriados de
T. nocturnum na concentração de $50 \mathrm{~g} \mathrm{~kg}^{-1}$ de grãos de milho, determinada pelas avaliações iniciais emlaboratório, foram introduzidos em garrafas de polietileno tereftalato (PET) de $2 \mathrm{~L}$ com perfurações em apenas uma face, para que somente o HCN entrasse em contato com a massa de grãos de milho, e a umidade emanada dos segmentos de caule verde das plantas fosse isolada.

O delineamento experimental foi inteiramente casualizado, com sete repetições, em parcelas subdivididas, considerando-se como parcela os tratamentos de fumigação e como subparcelas os intervalos de tempo consecutivos tomados a cada 23 dias para as avaliações. Foram avaliados os seguintes tratamentos de fumigação: $50 \mathrm{~g}$ de segmentos de caules verdes de $T$. nocturnum por quilograma de grãos de milho que continham, em média, entre $800 \mathrm{e}$ $900 \mathrm{mg} \mathrm{kg}^{-1}$ de HCN; $60 \mathrm{mg}$ de pastilhas de fosfeto de alumínio por quilograma de grãos de milho com $57 \%$ do princípio ativo; testemunha (sem aplicação). Cada unidade experimental foi tratada individualmente com o produto e, logo em seguida, recoberta com lona de plástico por quatro dias.

Os tratamentos foram aplicados aos 23 e 92 dias da experimentação, com duração de 207 dias. A cada 23 dias, foram retiradas de cada saco amostras de $100 \mathrm{~cm}^{3}$ de grãos para avaliação do grau de umidade, utilizando-se o aparelho eletrônico de precisão Geole 400 (Gehaka, São Paulo, SP), e de infestação, conforme as Regras para Análises de Sementes (Brasil, 1992). Foi determinada ainda a perda de peso de grãos, pelo método de Martins et al.(1984/1985). Antes de cada coleta, os sacos foram revolvidos para homogeneizar a distribuição tanto dos grãos danificados e sadios como dos insetos vivos e mortos, uma vez que há controvérsias quanto à distribuição de S. zeamais na massa de grãos armazenados, se é agregada ou uniforme (Hagstrum, 2000; Santos et al., 2003). Os dados percentuais foram submetidos à transformação arc sen $x^{0,5}$. Foi utilizado programa de análises estatísticas SAS (SAS Institute, 2001) para a análise de variância, e os valores médios das variáveis de cada tratamento foram comparados pelo teste de Tukey, a 5\% de probabilidade.

\section{Resultados e Discussão}

Os teores de ácido cianídrico na matéria verde das diferentes estruturas das plantas de $T$. nocturnum apresentaram, ao longo do ano, uma variação de $799,1 \mathrm{mg} \mathrm{kg}^{-1}$ em caules finos durante a época de 
seca, a $3.014,7 \mathrm{mg} \mathrm{kg}^{-1} \mathrm{em}$ folhas novas durante o período chuvoso (Figura 1). Esses valores podem ser considerados elevados em comparação à diversas espécies vegetais cianogênicas estudadas por Buhrmester et al. (2000), Valle et al. (2004) e Miller et al. (2006).

Muitas plantas são capazes de sintetizar compostos que liberam ácido cianídrico quando o tecido vegetal é danificado. Esses compostos podem ser cianoglicosídeos ou cianolipídios que, quando hidrolisados por enzimas, formam açúcares, ácidos graxos, aldeídos ou cetona juntamente com ácido cianídrico (Buhrmester et al., 2000).

Independentemente da parte das plantas de T. nocturnum avaliada, os maiores teores de HCN foram observados no período chuvoso do ano, quando variaram de $1.848,7 \mathrm{mg} \mathrm{kg}^{-1}$ em caules grossos a $3.014,7 \mathrm{mg} \mathrm{kg}^{-1} \mathrm{em}$ folhas novas. Tal resultado sugere uma forte influência do regime pluviométrico na produção desse metabólito secundário.

A análise de regressão apontou significância $(\mathrm{p}=0,045)$ para a relação quadrática das concentrações dos caules de T. nocturnum $\mathrm{x}$ mortalidade de adultos de S. zeamais (Figura 2).

Pode-se observar que o aumento das concentrações dos caules finos de T. nocturnum correspondeu a um aumento da mortalidade de $S$. zeamais, que atingiu seu valor máximo a $50 \mathrm{~g} \mathrm{~kg}^{-1}$, concentração adotada para ser utilizada na fase experimental em paiol. A partir dessa concentração, não houve alteração dos valores da mortalidade, que permaneceu em quase $100 \%$.

Os valores do grau de umidade dos grãos não apresentaram diferença significativa durante $o$

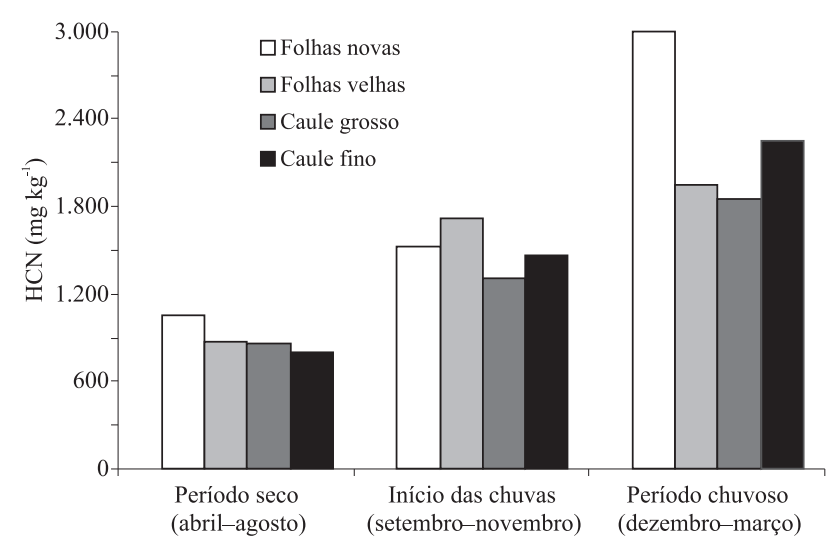

Figura 1. Teores de ácido cianídrico $(\mathrm{HCN})$ em folhas e caules de Tanaecium nocturnum em razão da época de coleta. período experimental. A média dos tratamentos foi de $14,3 \pm 0,1 \% ; 14,1 \pm 0,1 \%$ e $14,1 \pm 0,2 \%$ para T. nocturnum, fosfeto de alumínio e testemunha, respectivamente. Nas quatro avaliações iniciais, observou-se que, independentemente do tratamento, a umidade dos grãos de milho permaneceu em torno de 13\% (Figura 3), o que é considerado ideal para o armazenamento, principalmente de sementes, segundo Lollato (1989). No entanto, a partir da quarta avaliação, quando os tratamentos de expurgo foram novamente aplicados, constatou-se que a umidade dos grãos aumentou para valores próximos a $15 \%$ e permaneceu nesse patamar até o final do período experimental.

Quanto à infestação de S. zeamais, não houve diferença entre os tratamentos com segmentos de caules de $T$. nocturnum e fosfeto de alumínio até 184 dias após a aplicação dos fumigantes. Ambos diferiram da testemunha $(p<0,0001)$ durante esse período (Tabela 1). Foi observada uma diferença entre o tempo de proteção dos grãos de milho proporcionado pelos dois fumigantes avaliados. O fosfeto de alumínio apresentou maior eficácia e manteve os mesmos valores de infestação por $S$. zeamais durante o período experimental. Os valores da infestação dos grãos tratados com caule de T. nocturnum não diferiram dos valores de infestação dos grãos tratados com fosfeto de alumínio até 138 dias após a aplicação, o que sugere a necessidade de uma reaplicação de caules após esse período.

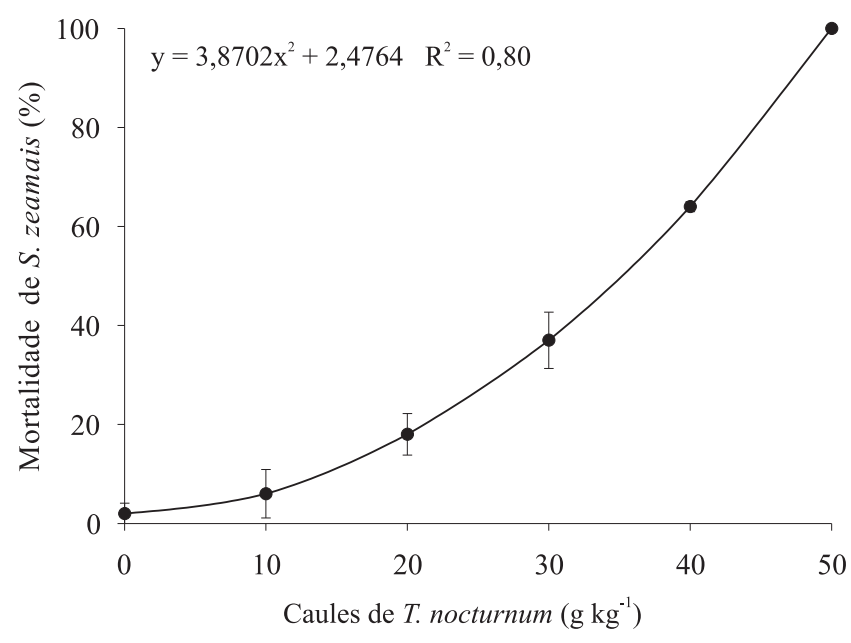

Figura 2. Curva de resposta da mortalidade de adultos de Sitophilus zeamais em razão de concentrações crescentes de segmentos de caules de Tanaecium nocturnum na massa de grãos de milho utilizados na fumigação do milho armazenado. 
De maneira geral, os baixos valores de infestação observados nesses tratamentos sugerem uma equivalência deles na eficácia de promoção da mortalidade de $S$. zeamais, do que se pode inferir que o efeito fumigante do caule de T. nocturnum pode estar relacionado à alta capacidade de difusão do $\mathrm{HCN}$ produzido por essa planta.

Celaro (2002) aponta como principal propriedade de um fumigante a sua capacidade de difusão na massa de grãos, pois a difusão de um gás depende principalmente de seu peso molecular e seu ponto de ebulição. Quanto menores esses valores, maior é a velocidade de difusão.

Com relação à perda de peso de grãos, em razão do ataque de $S$. zeamais, não houve diferença entre o tratamento com fosfeto de alumínio e com caule de $T$. nocturnum ao longo do período experimental (Tabela 2). Ambos diferiram da testemunha, que apresentou um aumento significativo nos valores de perda de peso quando comparada a esses dois tratamentos de fumigação logo no início do período de armazenamento (46 dias). Aos 207 dias, o valor da perda de peso foi de $38 \%$ nas parcelas não tratadas, que diferiram $(p<0,0001)$ dos tratamentos de fumigação, cujos valores foram de $18 \%$ tanto para o fosfeto de alumínio quanto para o caule de T. nocturnum.

De maneira geral, os valores de perda de peso foram crescentes em todos os tratamentos avaliados durante o período de armazenamento, e podem ser considerados elevados quando comparados aos valores esperados

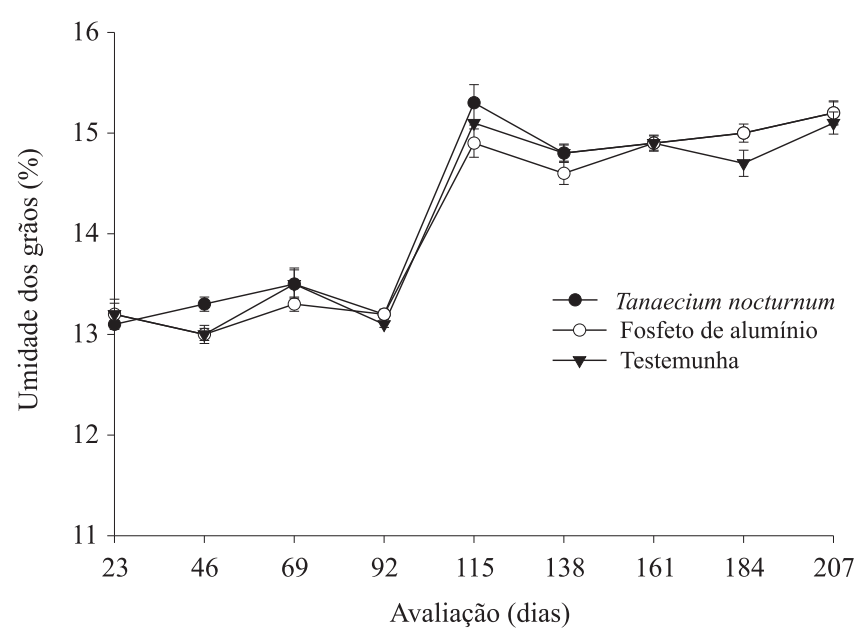

Figura 3. Umidade dos grãos de milho armazenados submetidos aos tratamentos de fumigação em função do período de armazenamento de 207 dias, avaliado a cada 23 dias. utilizando-se a relação linear entre essas variáveis, estabelecida por Santos \& Mantovani (1997) para 20 cultivares comerciais de milho em Minas Gerais. Para os valores de infestação de 3, 16,4 e 52\% (Tabela 1), essa relação linear projetaria valores de perdas de peso de $0,03,3,72$ e $13,7 \%$ para os grãos de milho tratados com fosfeto de alumínio, caules de T. nocturnum e testemunha, respectivamente. Mesmo assim, a diferença de praticamente $13 \%$ de infestação observada entre os tratamentos com fosfeto de alumínio e T. nocturnum ao final de 207 dias não se refletiu em uma diferença significativa na perda de peso dos grãos de milho tratados com esses produtos (Tabela 2), o que indica que esse controle alternativo pode ser adaptado às condições de armazenamento do milho em pequenas propriedades da Amazônia Ocidental.

Tabela 1. Efeito da aplicação de caules de Tanaecium nocturnum e fosfeto de alumínio na infestação de grãos de milho por Sitophilus zeamais (\%), em 207 dias de armazenamento $^{(1)}$.

\begin{tabular}{lcccc}
\hline Armazenamento (dia) & $\begin{array}{c}\text { T. nocturnum } \\
\text { alumínio }\end{array}$ & $\begin{array}{c}\text { Fosfeto de } \\
\text { Testemunha }\end{array}$ & $\begin{array}{c}\mathrm{CV} \\
(\%)\end{array}$ \\
\hline 23 & $2,3 \mathrm{Aa}$ & $2,7 \mathrm{Aa}$ & $2,8 \mathrm{Aa}$ & 21,6 \\
46 & $1,9 \mathrm{Aa}$ & $2,4 \mathrm{Aa}$ & $6,1 \mathrm{ABb}$ & 16,0 \\
69 & $2,7 \mathrm{ABa}$ & $2,2 \mathrm{Aa}$ & $8,8 \mathrm{ABb}$ & 20,9 \\
92 & $2,3 \mathrm{Aa}$ & $2,1 \mathrm{Aa}$ & $10,7 \mathrm{ABCb}$ & 17,2 \\
115 & $2,9 \mathrm{ABCa}$ & $1,6 \mathrm{Aa}$ & $11,8 \mathrm{BCb}$ & 16,3 \\
138 & $3,0 \mathrm{ABCa}$ & $2,2 \mathrm{Aa}$ & $12,0 \mathrm{BCb}$ & 19,4 \\
161 & $5,2 \mathrm{BCa}$ & $2,9 \mathrm{Aa}$ & $24,1 \mathrm{CDb}$ & 22,3 \\
184 & $5,8 \mathrm{Ca}$ & $3,4 \mathrm{Aa}$ & $34,5 \mathrm{DEb}$ & 22,5 \\
207 & $16,4 \mathrm{Db}$ & $3,0 \mathrm{Aa}$ & $51,7 \mathrm{Ec}$ & 20,8 \\
\hline $\mathrm{CV}(\%)$ & 19,4 & 23,3 & 23,2 & \\
\hline
\end{tabular}

${ }^{(1)}$ Médias seguidas de letras iguais, maiúsculas na coluna e minúsculas nas linhas, não diferem entre si pelo teste de Tukey, a 5\% de probabilidade.

Tabela 2. Efeito da aplicação de caules de Tanaecium nocturnum e fosfeto de alumínio na perda de peso de grãos de milho (\%) causada por Sitophilus zeamais, em 207 dias de armazenamento $^{(1)}$.

\begin{tabular}{lclll}
\hline Armazenamento (dia) & T. nocturnum & $\begin{array}{c}\text { Fosfeto de } \\
\text { alumínio }\end{array}$ & Testemunha & $\begin{array}{c}\mathrm{CV} \\
(\%)\end{array}$ \\
\hline 23 & $16,8 \mathrm{Aa}$ & $16,7 \mathrm{Ba}$ & $17,2 \mathrm{ABa}$ & 22,8 \\
46 & $19,1 \mathrm{Aab}$ & $15,3 \mathrm{ABa}$ & $30,0 \mathrm{BCb}$ & 22,5 \\
69 & $13,9 \mathrm{Aa}$ & $7,6 \mathrm{Aa}$ & $32,1 \mathrm{BCb}$ & 19,9 \\
92 & $17,5 \mathrm{Aa}$ & $12,6 \mathrm{ABa}$ & $37,9 \mathrm{Cb}$ & 19,9 \\
115 & $15,6 \mathrm{Aa}$ & $17,2 \mathrm{Ba}$ & $38,9 \mathrm{Cb}$ & 16,6 \\
138 & $15,2 \mathrm{Aa}$ & $16,8 \mathrm{Ba}$ & $30,1 \mathrm{BCb}$ & 12,0 \\
161 & $14,6 \mathrm{Aa}$ & $16,2 \mathrm{ABa}$ & $31,9 \mathrm{BCb}$ & 11,0 \\
184 & $11,9 \mathrm{Aa}$ & $16,7 \mathrm{Ba}$ & $37,2 \mathrm{Cb}$ & 11,4 \\
207 & $17,6 \mathrm{Aa}$ & $17,6 \mathrm{Ba}$ & $38,4 \mathrm{Cb}$ & 16,4 \\
\hline $\mathrm{CV}(\%)$ & 18,3 & 18,4 & 15,6 & \\
\hline
\end{tabular}

${ }^{(1)}$ Médias seguidas de letras iguais, maiúsculas na coluna e minúsculas nas linhas, não diferem entre si pelo teste de Tukey, a $5 \%$ de probabilidade. 


\section{Conclusão}

A utilização de $50 \mathrm{~g} \mathrm{~kg}^{-1}$ de segmentos do caule de T. nocturnum para o controle de $S$. zeamais proporciona redução da infestação da praga e da perda de peso de grãos de milho comparável à do fosfeto de alumínio.

\section{Referências}

BRADBURY, M.G.; EGAN, S.V.; BRADBURY, J.H. Picrate paper kits for determination of total cyanogens in cassava roots and all forms of cyanogens in cassava products. Journal of The Science of Food and Agriculture, v.79, p.593-601, 1999.

BRASIL. Ministério daAgricultura. Regras para análise de sementes. Brasília: Coordenação de Laboratório Vegetal, 1992. 365p.

BUHRMESTER, R.A.; EBINGER, J.E.; SEIGLER, D.S. Sambunigrin and cyanogenic variability in populations of Sambucus canadensis L. (Caprifoliaceae). Biochemical Systematics and Ecology, v.28, p.689-695, 2000.

CASTRO, H.G. de; FERREIRA, F.A.; SILVA, D.J.H. da; MOSQUIM, P.R. Contribuição ao estudo das plantas medicinais: metabólitos secundários. 2.ed. Viçosa: Visconde do Rio Branco, 2004.113p.

CELARO, J.C. Métodos curativos de controle de pragas de grãos armazenados. In: LORINI, I.; MIIKE, L.H.; SCUSSEL, V.M. (Ed.). Armazenagem de grãos. Campinas: Instituto Bio Geneziz, 2002. 983p.

COITINHO, R.L.B. de C.; OLIVEIRA, J.V. de; GONDIN JUNIOR, M.G.C.; CÂMARA, C.A.G. da. Toxicidade de óleos vegetais para adultos de Sitophilus zeamais Mots. (Coleoptera: Curculionidae) em grãos de milho armazenados. Revista Brasileira de Armazenamento, v.31, p.29-34, 2006.

ESTRELA, J.L.V.; FAZOLIN, M.; CATANI, V.; ALÉCIO, M.R.; LIMA, M.S. de. Toxicidade de óleos essenciais de Piper aduncum e Piper hispidinervum em Sitophilus zeamais. Pesquisa Agropecuária Brasileira, v.41, p.217-222, 2006.

FAZOLIN, M.; ESTRELA, J.L.V.; CATANI, V.; ALÉCIO, M.R.; LIMA, M.S. de. Atividade inseticida do óleo essencial de Tanaecium nocturnum (Barb. Rodr.) Bur. \& K. Shum. (Bignoneaceae) sobre Sitophilus zeamais Motsch. (Coleoptera: Curculionidae). Acta Amazonica, v.37, p.599-603, 2007.

GENTRY, A.H. A synopsis of Bignoniaceae ethnobotany and economic botany. Annals of the Missouri Botanical Garden, v.79, p.53-64, 1992.

GOTTLIEB, O.R.; KOKETSU, M.K.; MAGALHÃES, M.T.; MAIA, J.G.S.; MENDES, P.H.; ROCHA, A.I.; SILVA, M.L.; WILBERG, V.C. Óleos essenciais da Amazônia. Acta Amazonica, v.11, p.143-148, 1981.

HAGSTRUM, D.W. Using five sampling methods to measure insect distribution and abundance in bins storing wheat. Journal of Stored Products Research, v.36, p.253-262, 2000.
KERR,W.E.; POSEY,D.A. “Kangàrà Kanê” Tanaeciumnocturnum (Bignoniaceae), um cipó usado pelos índios Kayapós como inseticida natural. Acta Amazonica, v.7, p.23-26, 1991.

LOLLATTO, M.A. Colheita, processamento e armazenamento. In: INSTITUTO AGRONÔMICO DO PARANÁ. O feijão no Paraná. Londrina: IAPAR, 1989. p.281-303. (IAPAR. Circular técnica, 63).

MARTINS, D. dos S.; FARONI, L.R.D'A.; SILVA, F.A.P. da; SOUZA, O.F.F. de. Avaliação das perdas do milho, antes da colheita e no armazenamento, pelo gorgulho (Sitophilus spp.) e pela traça (Sitotroga cerealella) na microrregião de Viçosa, MG. Revista Brasileira de Armazenamento, v.9-10, p.6-8, 1984/1985.

MILLER, R.E.; JENSEN, R.; WOODROW, I.E. Frequency of cyanogenesis in tropical rainforests of far North Queensland, Australia. Annals of Botany, v.97, p. 1017-1044, 2006.

PAES, J.L. Difusão e sorção do isotiocianato alilo e seu efeito no controle de Sitophilus zeamais e na qualidade do milho. 2008. 54p. Dissertação (Mestrado) - Universidade Federal de Viçosa, Viçosa.

PIMENTEL, F.A. Avaliação fungitóxica e caracterização química dos óleos essenciais e extratos obtidos após diferentes processos de extração de cipó vick (Tanaecium nocturnum) e João-brandim (Piper piscatorum). 2007. 178p. Tese (Doutorado) - Universidade Federal de Lavras, Lavras.

PIMENTEL, M.A.G.; FARONI, L.R.D’A.; TÓTOLA, M.R.; GUEDES, R.N.C. Phosphine resistance, respiration rate and fitness consequences in stored-product insects. Pest Management Science, v.63, p.876-881, 2007.

REES, D.P. Coleoptera. In: SUBRAMANYAM, B.; HAGSTRUM, D.W. (Ed.). Integrated management of insects in stored products. New York: Marcel Dekker, 1996. p.1-39.

SANTOS, A.K.; FARONI, L.R.D'A.; SANTOS, J.P. dos; GUEDES, R.N.C.; ROZADO, A.F. Distribuição e amostragem de Sitophilus zeamais (M.) em grãos de trigo armazenado em silo metálico. Revista Brasileira de Engenharia Agrícola e Ambiental, v.7, p.505-512, 2003.

SANTOS, J.P. dos. Recomendações para o controle de pragas de grãos e de sementes armazenadas. In: BÜLL, L.T.; CANTARELLA, H. (Ed.). Cultura do milho: fatores que afetam a produtividade. Piracicaba: Potafos, 1993. p.197-236.

SANTOS, J.P. dos; MANTOVANI, E.C. Perdas de grãos na cultura do milho. Sete Lagoas: Embrapa-CNPMS, 1997. 40p. (Embrapa-CNPMS. Circular técnica, 24).

SAS INSTITUTE. SAS/STAT: user's guide. Cary: SAS Institute, 2001. 502p.

VALLE, T.L.; CARVALHO, C.R.L.; RAMOS, M.T.B; MÜHLEN, G.S.; VILLELA, O.V. Conteúdo cianogênico em progênies de mandioca originadas do cruzamento de variedades mansas e bravas. Bragantia, v.63, p.221-226, 2004.

Recebido em 10 de setembro de 2009 e aprovado em 1ำ de dezembro de 2009 